\title{
The effects of the headgear therapy on the airway dimensions in patients with class II malocclusion: A systematic review
}

\section{Wpływ aparatu headgear na wymiary drogi oddechowej pacjentów z wadą zgryzu klasy II - systematyczny przegląd piśmiennictwa}

\author{
Mojgan Shavakhi ${ }^{1, B, C}$, Fatemeh Mohamadian ${ }^{2, C, D}$, Hooman Zarif Najafi ${ }^{1, E, F}$ \\ ${ }^{1}$ School of Dentistry, Shiraz University of Medical Sciences, Iran \\ ${ }^{2}$ School of Dentistry, Shahid Beheshti University of Medical Sciences, Tehran, Iran \\ A - research concept and design; $\mathrm{B}$ - collection and/or assembly of data; $\mathrm{C}$ - data analysis and interpretation; \\ $\mathrm{D}$ - writing the article; $\mathrm{E}$ - critical revision of the article; $\mathrm{F}$ - final approval of the article
}

Address for correspondence

Fatemeh Mohamadian

E-mail: furstinfateme@gmail.com

Funding sources

None declared

Conflict of interest

None declared

Received on January 12, 2019

Reviewed on February 15, 2019

Accepted on March 26, 2019

Published online on June 28, 2019

\begin{abstract}
Class II malocclusion may be caused by the maxillary protrusion or the mandibular retrusion. One treatment method is to use a headgear, which might affect the dimensions of the patient's airway. The aim of this study was to assess the effect of a headgear on the airway dimensions in class II malocclusion patients. A digital search and a manual search were conducted for English-language articles published from January 2000 to December 2018 about human clinical trials, including the usage of a cervical headgear in class II malocclusion patients who had measurable changes in the airway and/or jaw size. The synthesis methods of the study consisted of data concerning the study design, the type of treatment device, the patient's age at the start, the sample size, the treatment duration, the type of radiography, and the results of treatment; this data was extracted and compared. The quality of the selected articles was assessed. All of the studies had a high risk of bias, providing low-quality evidence of the effectiveness of the headgear therapy on the airway dimensions. The conclusions of the articles differed from each other and there were different mechanisms of changes in the jaw or airway dimensions. Therefore, further studies are required to find the clearest results showing the effect of a cervical headgear in class II malocclusion.
\end{abstract}

Key words: headgear, airway dimensions, class II malocclusion

Słowa kluczowe: headgear, wymiary drogi oddechowej, wada zgryzu klasy II

Cite as

Shavakhi M, Mohamadian F, Zarif Najafi H. The effects

of the headgear therapy on the airway dimensions in patients with class II malocclusion: A systematic review. Dent Med Probl. 2019;56(2):191-196. doi:10.17219/dmp/105957

DOI

$10.17219 / \mathrm{dmp} / 105957$

Copyright

๑ 2019 by Wroclaw Medical University

This is an article distributed under the terms of the

Creative Commons Attribution 3.0 Unported License (CC BY 3.0)

(https://creativecommons.org/licenses/by/3.0/) 


\section{Introduction}

Patients with skeletal Class II malocclusion are characterized by excessive maxillary growth and/or mandibular deficiency. ${ }^{1,2}$ It has been shown that in Class II patients, the upper airway tends to be reduced ${ }^{3-5}$ and a correlation has been found between mandibular length and position and the size of the oropharynx and nasopharynx in these individuals. ${ }^{6,7}$ Furthermore, airway volume is decreased in Class II patients ${ }^{8}$ and the diminished upper airway plays an important role in oxygen saturation ${ }^{9}$ and in the development of obstructive sleep apnea (OSA), which is known as a sleep respiratory disorder. ${ }^{10,11}$ Since a significant relationship exists between the posterior airway and the position of the maxilla, mandible and soft palate ${ }^{12}$, any alteration in the positioning of the skeleton might lead to changes in airway sizes. ${ }^{10,13}$

Two major treatment options are available for Class II growing patients: functional appliances, which stimulate mandibular growth, ${ }^{14}$ and headgear treatment, which inhibits maxillary growth. ${ }^{15}$

Cervical headgear (CHG) with an expanded inner bow is commonly used for restricting maxillary forward growth and for arch expansion, ${ }^{16,17}$ and is typically designed for nighttime usage. The distal movement of the maxilla caused by such headgear seems to have an adverse effect on the size of the upper airway. ${ }^{18}$ However, it has been shown in some studies that CHG facilitates mandibular growth, which may lead to improved airway size. ${ }^{18-20}$ Some studies have shown that using CHG while sleeping decreases the size of the upper airway and may contribute to the occurrence of sleep apnea in patients with a history of OSA. ${ }^{19,21}$

Studies concerning the effects of headgear therapy on upper airway dimensions have reported conflicting results and the systematic reviews are focused on the effect of stimulating mandibular growth on the airway size. ${ }^{22,23}$ Based on the PICO framework, this review of the literature was aimed at assessing the changes in airway dimensions in preadolescent Class II patients treated with functional headgear.

\section{Material and methods}

\section{Search strategy}

A search of 5 electronic databases - PubMed/Medline, Google Scholar, EMBASE, Web of Science and Cochrane - was carried out for relevant English-language studies published between January 2000 and December 2018 using the following keywords separately and in combination: [headgear] AND [cl II malocclusion OR maxillary protrusion OR mandibular retrusion] AND [airway dimension OR upper airway size OR upper air- way width] AND [jaw growth]. In addition, a manual search was also performed for publications in dental and orthodontic-related journals from January 2000 to December 2018 that were not electronically identified (including "The International Journal of Adult Orthodontic and Orthognathic Surgery" and "The Journal of General Orthodontics"). No other restrictions were established, and the free-text strategy and Medical Subject Headings terms $(\mathrm{MeSH})$ were applied in the search process. This systematic review was conducted in line with the Preferred Reporting Items for Systematic Reviews and Meta-Analyses statement (PRISMA) as illustrated in Fig. 1.

Our PICO criteria were constructed as follows: 1. Participants: humans with Class II malocclusion. 2. Intervention/Exposure: cervical head gear therapy. 3. Comparisons: treatment with headgear vs. other Class II malocclusion treatments. 4. Outcome: the effect of headgear therapy on airway dimensions

\section{Study selection and eligibility criteria}

In order to select relevant studies, the extracted sources were evaluated by 2 independent reviewers. In case of disagreement, the final assessment was made by a $3^{\text {rd }}$ reviewer. The criteria used to evaluate eligibility were defined according to the considered subject of the present article. The current article only considers original research with the following specifications: Randomized Controlled Trials (RCTs) in addition to cohort and cross-sectional sources discussing the impact of head gear therapy on the dimensions of the airway in Class II malocclusion, and human clinical studies focused on the use of headgear in patients with Class II malocclusion who did not have any respiratory problems before

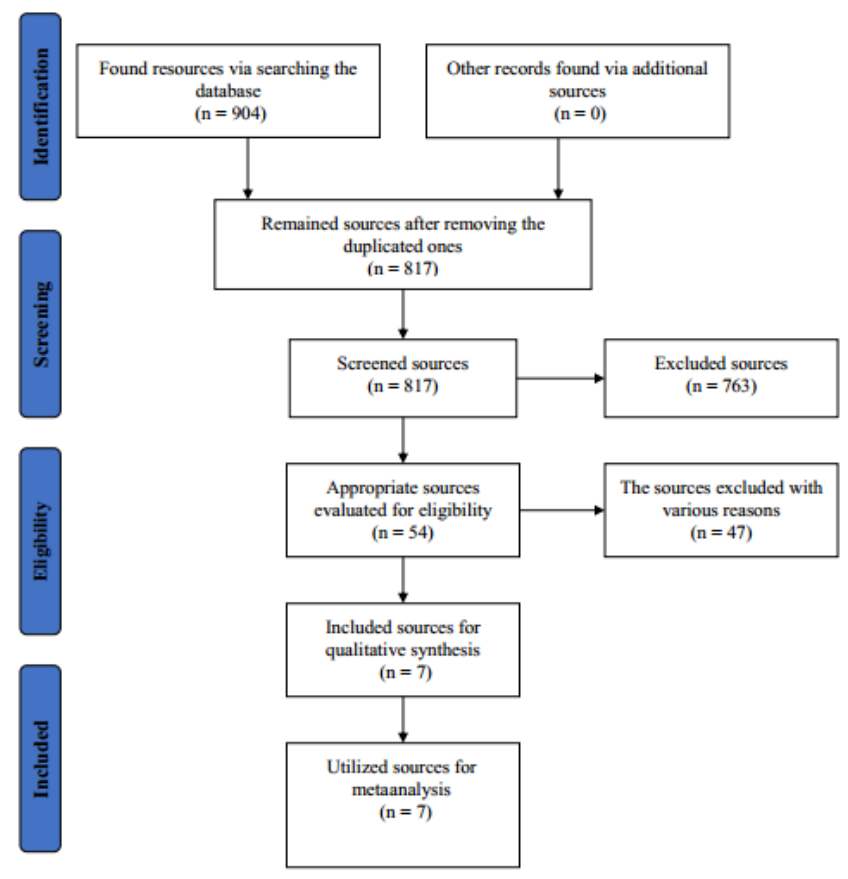

Fig. 1. PRISMA diagram of the present study 
the examination. Descriptive-type observational studies (e.g., case studies) and review articles, chapters of books, reports and studies focused on nonhuman cases were excluded from the current study. Moreover, the sources which did not consider changes in the size of the airway were not included in the present review article. In addition, only sources written in English were considered. The primary screening of the subjects and abstracts was performed on the basis of the above-mentioned criteria. It should be noted that all sample sizes were considered for this review study and that any duplicate sources were identified and removed. The data was then extracted from the eligible sources and the extracted information was analyzed in the next step of the study. The features of the studies used for review and the summary of their results are presented in Table 1 .

\section{Results}

\section{Study selection}

The search initially retrieved a total of 54 citations. Following the primary screening of titles and abstracts and the final screening of full texts, 7 studies met the inclusion criteria and were included in the final evaluation.

\section{Study characteristics}

The data of study design, type of treatment device, patient's age at the start, sample size, treatment duration, radiographic type and the results of treatment were extracted and compared (Table 1).

\section{Risk of assessment bias}

All selected studies were judged to have a high risk of bias (Table 2), providing low-quality evidence on the effectiveness of headgear therapy on airway dimensions.

\section{Data comparison}

\section{Use of headgear and diagnostic tool}

Head gear was used in all studies alone or in combination with other devices. Two studies used an activator as well ${ }^{24,25}$ and 1 used Class II traction. ${ }^{26}$ Each of the 7 articles selected cephalometry as a diagnostic tool. ${ }^{17-19,24-27}$

\section{Sample size}

Different sample sizes were selected for the included studies, which ranged from 10 to 209 patients. ${ }^{17-19,24-27}$

\section{Patients' age}

Some variation was found in the age of the patients. One study treated adults, ${ }^{12}$ while the others treated children aged 7.2 to 11.9 years old ${ }^{17,18,24,26,27} ; 1$ did not mention the patients' age. ${ }^{25}$

\section{Treatment duration}

The duration of treatment was different, varying from 3.5 months to 6.4 years ${ }^{17,18,24-27}$ and 1 study did not report the treatment duration time. ${ }^{19}$

\section{Treatment outcome}

The outcomes of head gear treatment were reported in different ways. Two studies did not report any changes in upper airway dimensions ${ }^{18,25}, 1$ demonstrated an increase in the upper airway size ${ }^{26}$ while another reported a decrease in sagittal dimensions and no change in vertical dimensions. ${ }^{19}$ Four articles reported an increase in retropalatal $^{17,27}$ and pharyngeal airway sizes. ${ }^{24,25}$ One experiment found a decrease in the size of the opening of the jaw after treatment. ${ }^{19}$ On the other hand, no significant change was mentioned in another study for anteroposterior displacement of the mandible. ${ }^{12}$ Two studies evaluated changes of the hyoid bone. ${ }^{19,26}$ One of the studies reported a significant forward displacement of the hyoid, ${ }^{19}$ whereas the other one just mentioned a change in the position of the hyoid. ${ }^{26}$ One article assessed the movement of the $3^{\text {rd }}$ cervical vertebra and showed that it had moved forward significantly. ${ }^{19}$ ANB was one of the main parts that were investigated in the studies: 2 studies defined a reduction in ANB after treatment, ${ }^{18,24}$ while the other only mentioned a change in $\mathrm{ANB}{ }^{26}$ In 1 paper, a significant change was reported for SNB, A and Wits. ${ }^{26}$ Overjet, overbite and lip measurements had decreased in 1 study. ${ }^{26}$ In 1 paper, pharyngeal width was assessed in OSA patients and a decrease was reported. ${ }^{25}$ A significant posterior movement of the maxilla was demonstrated among the males in one experiment. ${ }^{27} \mathrm{~A}$ decrease in the palatomandibular angle was reported in one study. ${ }^{27}$

\section{Discussion}

The development and growth of dentoskeletal features are affected by several physiological factors, such as the circadian rhythm, fluctuations in hormone levels and metabolic activity. ${ }^{19}$ Class II malocclusion could be caused by a maxillary protrusion or a mandibular retrusion. ${ }^{18}$ The treatment protocol focuses on restricting maxillary growth and enhancing mandibular growth, which can affect the positions of the jaw and upper airway. ${ }^{18}$ Some studies have been performed to assess the outcomes of headgear therapy on upper airway dimensions in such patients. ${ }^{18}$ 


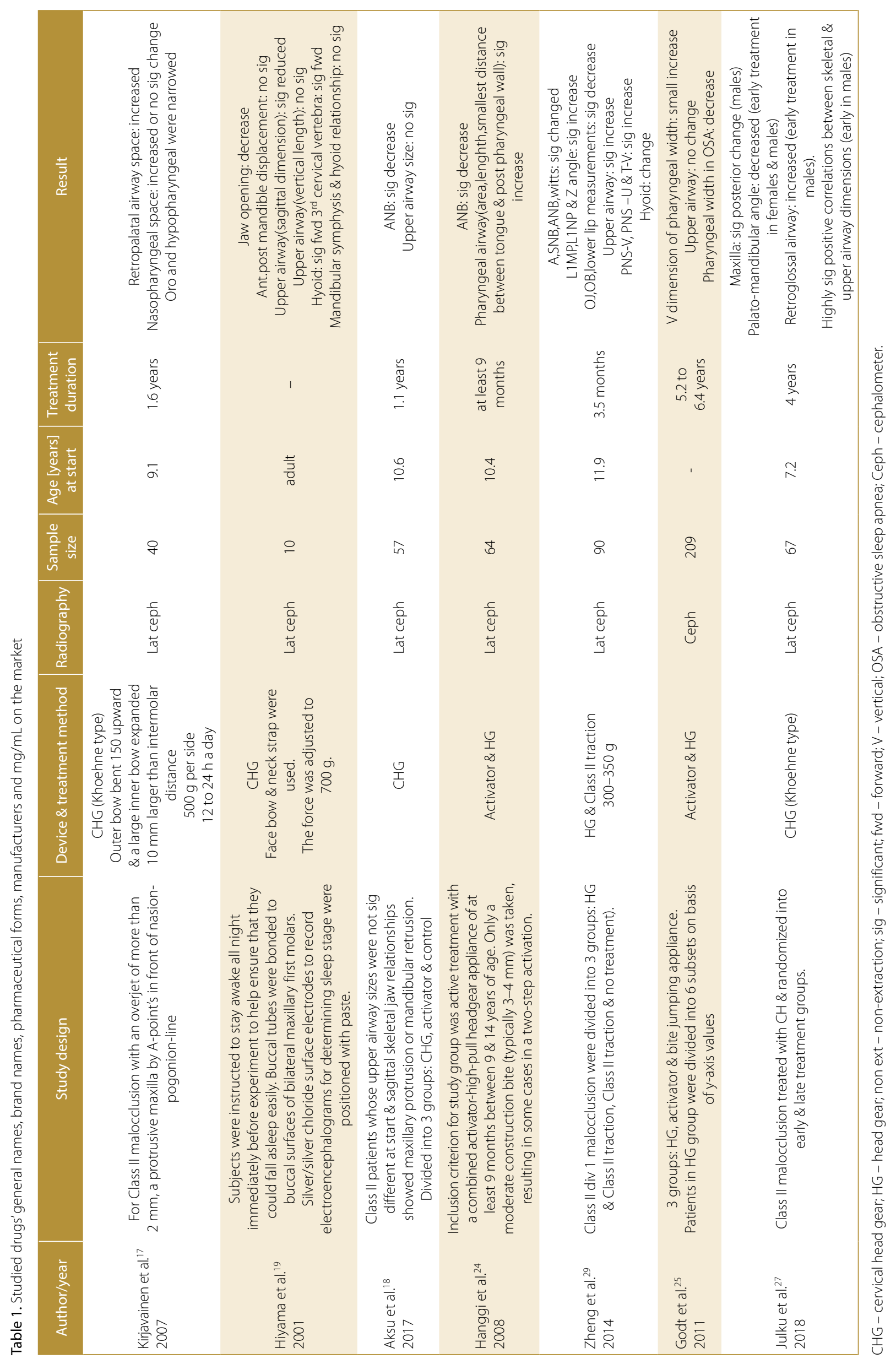


Table 2. Parameters used for quality assessment

\begin{tabular}{|c|c|c|c|c|c|}
\hline Study & Randomization & Control group & Blind & Follow-up & Estimated risk of bias \\
\hline Kirjavainen et al. ${ }^{17}$ & unclear & yes & yes & yes & high \\
\hline Hiyama et al. ${ }^{19}$ & unclear & no & unclear & yes & high \\
\hline Aksu et al. ${ }^{18}$ & unclear & yes & unclear & yes & high \\
\hline Hanggi et al. ${ }^{24}$ & yes & yes & unclear & yes & high \\
\hline Zheng et al. ${ }^{29}$ & unclear & yes & unclear & yes & high \\
\hline Godt et al. ${ }^{25}$ & unclear & no & unclear & yes & high \\
\hline Julku et al. ${ }^{27}$ & yes & no & unclear & yes & high \\
\hline
\end{tabular}

\section{Effect on the upper airway}

The effect of CHG on the upper airway is limited to the nose, nasopharynx and retropalatalarea. ${ }^{17}$ Although nasal breathing can be improved by increasing the lateronasal width and retropalatal airway, this effect may not be clinically significant. ${ }^{17} \mathrm{~A}$ few studies have investigated the features of the upper airway in a supine position - which is similar to sleep positions - because these features and the position of the tongue depend on the position of the body. ${ }^{26,28}$ During sleep, the involvement of tonic muscles is reduced, depending on the stage of sleep. ${ }^{26,28}$ The respiratory phase plays an important role in the position and morphology of the oropharynx. ${ }^{19}$ Based on this rule, Hiyama et al. recorded all cephalograms at the end of expiration. ${ }^{19} \mathrm{~A}$ decrease in the upper airway sagittal dimension after using CHG might affect the respiratory function during sleep. ${ }^{19}$ Kirjavainen et al. ${ }^{17}$ demonstrated that the retropalatal area was wider after CHG treatment in children; however, Godt et al. ${ }^{25}$ reported minor or no changes in anteroposterior pharyngeal width. On the other hand, 1 study declared that there are various sizes of airways among patients and this is independent of the skeletal parameters since the mechanism is more complex; for example, different positions of the tongue or catch-up growth and its effect on oropharyngeal dimensions. ${ }^{18}$ Therefore, there are considerable individual differences in normal growth and in the response to treatment. ${ }^{24}$

\section{Effect on the mandible}

Some studies have demonstrated that CHG induces a forward displacement of the mandible in conscious patients; therefore, dilation of the upper airway can be achieved by applying pressure on the back of the neck with the neck strap. ${ }^{19}$ Previous studies have reported that pushing the surrounding soft tissue of the neck anteriorly may cause passive superoanterior rotation of the mandible, regardless of the neuromuscular mechanism. ${ }^{19}$ Mandibular position is affected by sleep stage, and during NREM sleep it opens progressively more. ${ }^{19}$ Utilizing CHG during sleep does not cause significant forward mandible displacement; on the contrary, such displacement in conscious patients can facilitate mandibular growth. ${ }^{19}$ Therefore, clinicians must pay attention to the instructions accompanying the CHG. ${ }^{19}$
Hiyama et al. suggested that the mandible does not move anteroposteriorly and that only a counterclockwise mandible rotation was noticed, which also led to an increase in the dimensions of the upper airway. ${ }^{19}$ On the other hand, a decrease in N-Me after wearing CHG confirms this counterclockwise rotation. In the cases of obstructive sleep apnea, the mandibles were more open than the mandibles of normal cases during sleep and such jaw opening during sleep was suggested to potentially result in the obstruction of the upper airway in patients with OSA. ${ }^{19}$

\section{Effect on the maxilla}

Though there is a common assumption that CHG restricts the growth of the maxilla in the forward direction, no restriction in the growth of the palatal plane (ANSPNS) was observed - on the contrary, palatal plane length increased. ${ }^{17}$ The restriction of the maxillary growth after treatment is limited to the alveolar process, which can affect the growth of the nose. ${ }^{17}$ Hanggi et al. reported that the combined activator and high-pull headgear had a significant impact on the maxilla. ${ }^{24}$

\section{Effect on the angle of soft and hard tissue}

Although it has been demonstrated that the angle between the palatal plane and the tip of the soft palate decreased during treatment, this alteration does not correlate with a change in the dimensions of the retropalatal airway space. ${ }^{17}$ Some of the decrease in this angle is due to the anterior downward rotation of the palatal plane instead of a change in the position of the uvula. ${ }^{17}$

\section{Effect on the hyoid}

In children with Class II malocclusion, the hyoid bone position was higher; however, after CHG treatment it moved forward but not higher. ${ }^{19}$ On the other hand, the third vertebra moved forward as well and resulted in the same distance between the hyoid and the third vertebra. ${ }^{19}$ Therefore, the vertical length of the upper airway cannot be affected by wearing CHG ${ }^{19}$ The hyoid bone gradually moved forward and downward from mixed dentition to permanent dentition. ${ }^{29}$ 


\section{Conclusions}

Considering the discrepancies in the literature, it can be concluded that the dimensions of different parts of the upper airway - such as sagittal dimension, vertical length and retropalatal width - demonstrated various responses to headgear treatment and that individual differences in normal growth play an important role in the response to treatment. Most of the studies agree that headgear therapy does not move the mandible anteroposteriorly and that only counterclockwise mandible rotation may be noticed. This can lead to an increase in the size of the upper airway, though the maxillary growth is limited to the alveolar process after CHG treatment.

\section{ORCID iDs}

Mojgan Shavakhi (1) https://orcid.org/0000-0002-7013-6048 Fatemeh Mohamadian (1) https://orcid.org/0000-0002-8055-8762 Hooman Zarif Najafi @ https://orcid.org/0000-0002-1516-8880

\section{References}

1. Craig CE. The skeletal patterns characteristic of class I and class II, division I malocclusions in norma lateralis. Angle Orthod. 1951;21(1):44-56.

2. Altemus LA. Horizontal and vertical dentofacial relationships in normal and class II division I malocclusion in girls 11-15 years. Angle Orthod. 1955;25:120-137.

3. Bollhalder J, Hänggi MP, Schätzle M, Markic G, Roos M, Peltomäki TA. Dentofacial and upper airway characteristics of mild and severe class II division 1 subjects. Eur J Orthod. 2013;35(4):447-453.

4. Mergen DC, Jacobs RM. The size of nasopharynx associated with normal occlusion and class II malocclusion. Angle Orthod. 1970;40(4):342-346.

5. Joseph AA, Elbaum J, Cisneros GJ, Eisig SB. A cephalometric comparative study of the soft tissue airway dimensions in persons with hyperdivergent and normodivergent facial patterns. J Oral Maxillofac Surg. 1998;56(2):135-139.

6. e Silva NN, Wanderley Lacerda RH, Cunha Silva AW, Braga Ramos T. Assessment of upper airways measurements in patients with mandibular skeletal class II malocclusion. Dental Press J Orthod. 2015;20(5):86-93.

7. de Freitas MR, Alcazar NM, Janson G, de Freitas KM, Henriques JF. Upper and lower pharyngeal airways in subjects with class I and class II malocclusions and different growth patterns. Am J Orthod Dentofacial Orthop. 2006;130(6):742-745.

8. Chèze $B$, Gastineau $P$, Chevallier J. Forecasting world and regional aviation jet fuel demands to the mid-term (2025). Energy Policy. 2011;39(9):5147-5158.

9. Partinen M, Guilleminault C, Quera-Salva MA, Jamieson A. Obstructive sleep apnea and cephalometric roentgenograms. The role of anatomic upper airway abnormalities in the definition of abnormal breathing during sleep. Chest. 1988;93(6):1199-1205.

10. Hochban W, Brandenburg U. Morphology of the viscerocranium in obstructive sleep apnoea syndrome - cephalometric evaluation of 400 patients. J Craniomaxillofac Surg. 1994;22(4):205-213.

11. Kiely JL, Deegan PC, McNicholas WT. Resolution of obstructive sleep apnoea with growth in the Robin sequence. Eur Respir J. 1998;12(2):499-501.

12. Muto T, Yamazaki A, Takeda S, et al. Relationship between the pharyngeal airway space and craniofacial morphology, taking into account head posture. Int J Oral Maxillofac Surg. 2006;35(2):132-136.

13. deBerry-Borowiecki B, Kukwa A, Blanks RH. Cephalometric analysis for diagnosis and treatment of obstructive sleep apnea. Laryngoscope. 1988;98(2):226-234.
14. Tümer N, Gültan AS. Comparison of the effects of monoblock and twin-block appliances on the skeletal and dentoalveolar structures. Am J Orthod Dentofacial Orthop. 1999;116(4):460-468.

15. Lima Filho RM, Lima AL, de Oliveira Ruellas AC. Longitudinal study of anteroposterior and vertical maxillary changes in skeletal class II patients treated with Kloehn cervical headgear. Angle Orthod. 2003;73(2):187-193.

16. Meach CL. A cephalometric comparison of bony profile changes in class II, division 1 patients treated with extraoral force and functional jaw orthopedics. Am J Orthod. 1966;52(5):353-370.

17. Kirjavainen $M$, Kirjavainen $T$. Upper airway dimensions in class II malocclusion. Effects of headgear treatment. Angle Orthod. 2007;77(6):1046-1053.

18. Aksu M, Gorucu-Coskuner H, Taner T. Assessment of upper airway size after orthopedic treatment for maxillary protrusion or mandibular retrusion. Am J Orthod Dentofacial Orthop. 2017;152(3):364-370.

19. Hiyama $S$, Ono $T$, Ishiwata $Y$, Kuroda $T$. Changes in mandibular position and upper airway dimension by wearing cervical headgear during sleep. Am J Orthod Dentofacial Orthop. 2001;120(2):160-168.

20. Graber TM. Orthodontics principles and practice [in Spanish]. Bolet Odontol (Bogota). 1968;34(393):62-70.

21. Pirilä-Parkkinen $K$, Pirttiniemi $P$, Nieminen $P$, et al. Cervical headgear therapy as a factor in obstructive sleep apnea syndrome. Pediatr Dent. 1999;21:39-45.

22. Kannan A, Sathyanarayana HP, Padmanabhan S. Effect of functional appliances on the airway dimensions in patients with skeletal class II malocclusion: A systematic review. J Orthod Sci. 2017;6(2):54-64.

23. Xiang M, Hu B, Liu Y, Sun J, Song J. Changes in airway dimensions following functional appliances in growing patients with skeletal class II malocclusion: A systematic review and meta-analysis. Int J Pediatr Otorhinolaryngol. 2017;97:170-180.

24. Hänggi PM, Teuscher MU, Roos M, Peltomäki T. Long-term changes in pharyngeal airway dimensions following activator-headgear and fixed appliance treatment. Eur J Orthod. 2008;30(6):598-605.

25. Godt A, Koos B, Hagen H, Göz G. Changes in upper airway width associated with class II treatments (headgear vs activator) and different growth patterns. Angle Orthod. 2011;81(3):440-446.

26. Chase MH, McGinty DJ, Sterman MB. Cyclic variation in the amplitude of a brain stem reflex during sleep and wakefulness. Experientia. 1968;24(1):47-48

27. Julku J, Pirilä-Parkkinen K, Pirttiniemi P. Airway and hard tissue dimensions in children treated with early and later timed cervical headgear - a randomized controlled trial. Eur J Orthod. 2018;40(3):285-295.

28. Tangel DJ, Mezzanotte WS, Sandberg EJ, White DP. Influences of NREM sleep on the activity of tonic vs inspiratory phasic muscles in normal men. J Appl Physiol. 1992;73(3):1058-1066.

29. Zheng B, Jiang Z, Liu F, et al. Effect of headgear and class II traction on upper airway dimensions and hyoid bone position in non-extraction patients with class II division 1 malocclusion. J Hard Tissue Biol. 2015;24(1):1-6. 